\title{
A Contribution to Improve the Children's Catalogue of the Public Library
}

Una contribución para la mejora del catálogo infantil de la biblitoteca pública

\section{Sandra Cosme (1) y Paulo Quaresma (2)}

(1) Departamento de História, Universidade de Évora, Palácio do Vimioso, Apartado 94, 7002-554 Évora, Portugal, Sandracosme@simplesnet.pt (2) Departamento de Informática, Universidade de Évora, Rua

Romão Ramalho n5 59, 7000-671 Évora, Portugal, pq@di.uevora

\section{Resumen}

Esta comunicación tiene como objeto el catálogo Infanto Juvenil (IJ) de la Biblioteca Pública Portuguesa (BPP) y tiene como objetivo principal contribuir a su mejora. Se describe el contexto del paradigma comunicativo de la biblioteca contemporánea, como un encuadramiento que fundamenta una evolución del concepto de catálogo y hace emerger el concepto de catálogo infantil- juvenil. Se hace una identificación y caracterización de los catálogos, de las colecciones y de los espacios especialmente dedicados al público infantil- juvenil en 115 bibliotecas públicas Portuguesas (BPP). Se focalizan los catálogos dedicados a este público para encuadrar la futura implementación de una ontología que, interviniendo en la subestructura del catálogo, haga emerger as relaciones entre objetos y mejore el espacio de diálogo idealizado para el catálogo infantil- juvenil de la Biblioteca Pública.

Palabras clave: Catálogos infantiles y juveniles. Bibliotecas públicas. Ontología. Paradigma comunicativo.

\section{Communication paradigm of the contemporary library}

In face of the communication paradigm of the contemporary library characterized by a trend to emphasize the systems/organizations' functionality and by the potential designed in terms of dynamics of interaction, hermeneutical integrative principles emerge, enabling the exploration of new research spaces. These paths are located at a conciliation plane promoted by international principles that drive the convergence of the foundations and ambitions of the classical school of biblioteconomy both in theory and practice, generating in this way, an appropriate environment to manage the newly available source materials for a reformulated practice. It is in this space of interpretation, modeling, operationalization and construction, opened to theory and practice, that we also envision the integra-

\begin{abstract}
This paper presents a proposal whose main goal is to contribute for the improvement of the children's catalogue of the Portuguese Public Library. The context of the communicational paradigm of the contemporary library lays the foundation for an evolution of the concept of catalogue and purports the emergence of the concept of catalogue for children. The catalogues, the collections and the facilities and equipment infrastructures available to young publics in 115 Portuguese public libraries are identified and characterized. This survey is then used as a starting point for our proposal that suggests the implementation of an ontology that, by acting upon the catalogue's substructure, will expose new relations between objects and improve the dialogue space idealized for the children's catalogue of the Public Library.
\end{abstract}

Keywords: Children's catalogues. Public libraries. Ontology. Communication paradigm.

tion and fusion of the physical and digital space, in a highly disputed cyberspace. There is an openness attitude with emerging tools and sciences that intend to work on the source material in its primary form, based upon principles, in open, creative and trandisciplinary contexts.

In this new paradigm, with the possibility of regenerating the search spaces based on the increasing system's malleability becoming available, the interaction and cooperation between the user and the system/organization based on a dialogical attitude is allowed. A dialogue in which both parties can constitute themselves as players, overcoming the limitations of the traditional roles of sender and receiver, and recognizing in each individual its singularities and his or her aptitude to be a content producer. The traditional vehicles or communication links give place to more ergonomic spaces that supersede 
the mere information access by the users. They provide knowledge access, by trying to satisfy not only the user's needs but also to generate new questions and users. This way we shall produce a better environment where new knowledge spaces, more than simple information spaces, will eventually develop.

That is within this model of action that it is urgent to design spaces of question and answer to fulfill the natural demands of special users. We seek the "materialization" of a more ergonomic space, platform of knowledge, construction, e-learning and interaction that shall surpass the linear and unidimensional nature of the classical paradigm and its associated communication model.

\section{Goals}

The effort on the children's catalogue of the Portuguese Public Library, given a predominant emergence of a new communication paradigm, moves itself on a platform - the Functional Requirements for Bibliographic Records (FRBR) principles- with inspiring challenges: they assume a global view by integrating the participation of schools and other formerly divergent movements, achieving an international consensus about the cataloguing discipline; through the dynamics that they can enforce both to current and future collections' management; by the dialogue that they open to areas such as ontologies; and by the central role they assign to the user and target group.

Our goal is to facilitate the emergence of a space that shall assure the visibility of the requirements that our organizations shall satisfy, under transversal interaction of this articulation of principles. The "ontology, term used to denote the shared understanding of some domains of interest, often conceived as a set of classes (concepts), relations, functions, axioms and instances" (Ding, 2001), formalize languages that can enforce the application of these principles, collecting from databases and bibliographic records some of the basis material to achieve it, and complementing it with materials found in the digital space.

Having as our main goal the contribution for an improvement of the catalogue, we assume that it is possible to adapt the catalogues of the libraries to the children public. To achieve that, we need to identify and characterize the catalogues, the collections and the facilities especially devoted to the public under study, to understand how the process of attracting this public is evolving.

We want to define an improvement proposal based on a synergic articulation of applicable bodies of knowledge. This proposal will rely on an analysis of the services that are currently available interpreted in light of the communication model. We strategically surveyed for this purpose the main features of the existing catalogues.

\section{Methodology}

The study starts with a focus on several strategies so that a dialogical and transdisciplinary principle can be created to legitimate an approximation to the object from various standpoints.

To achieve a first global view of the service offers under study, we chose a quantitative methodology to assess the structuring elements that describe the children's service in the Portuguese Public Libraries.

We made a statistical analysis to the results of 115 surveyed Portuguese public libraries. The survey was built around three inter-related topics:

- the spatial and temporal identification of the children's public libraries;

- the survey of the main features of the interface available to access the children's collection, specifying the general features of the catalogue;

- the survey of the constituent objects of the collections and their inclusion (or not) in particular physical sub spaces.

We emphasize the study of catalogues targeted to children public and available online. The interface, the bibliographic description of the objects and the coherence of the representation of the objects available in the library and those described in the catalogue is subject to a more detailed analysis.

We rely on both the Guidelines for Children's Libraries Services (IFLA, 2003) and the Guidelines for the Online Public Access Catalogue Displays (OPACs) (IFLA 2003), the First Principles of Interaction Design and Ten Usability Heuristics (Nielsen Norman Group) to formulate and support the problem statement. We analyze these sources by means of interpretation, comparison and systematization, and apply the resulting perspective about them to formulate an improvement hypothesis.

The strategy to be followed to implement our improvement proposal consists in the conception and usage of an ontology as defined by Ying Ding: "refers to an abstract model of phenomena in the world by having identified the relevant concepts of those phenomena". The 
versatility designed in its principles allows for a submersion in the systems, collecting from its internal functional logic the materials needed for an extension to new construction spaces. That is why ontologies are a valid option for an improvement of existing catalogues that at the same time reinforces their strengths and corrects their weaknesses-a language able to develop the communication between paradigms, spaces and usage interests.

This synergy of resources and perspectives will allow a transversal ability that, although natural in our domain, assures the impossibility to observe the object from just one viewpoint, opening it to a fruitful hermeneutical construction.

\section{The catalogue as a space for navigation}

Nowadays, we can see the power built into the catalogues of some recent libraries, in the so called knowledge society. On the Online Computer Library Center (OCLC) network, among other possible examples, the catalogues that became noticeable by applying the FRBR, constituted themselves as powerful "search engines" through the physical and digital libraries and at the same time as spaces under continuous construction in which the user plays an active role.

The traditional definition of catalogue as a vehicle or link between the collection of a library and the user evolves though to the creation of more ambitious spaces, with broader functions. Computer supported first (Byrum, 2005), and online in the next stage, there's a generational evolution that was built based on the surpassing of the models. In the 90s, three generations of online catalogues' have been identified (Hildreth cited by Arellano, 1994). Each generation redesigned its service profile to overcome the problems recognized on previous generation catalogues.

Catalogues evolved by construction of a user interaction space that tries to know the user. In the third generation, it is prevalent the existence of a space in which the question is aided and supported by the system "with automatic spell checking; the automated location and presentation of related materials, and display of online references" (Arellano, 1994).

At the beginning of the century the presentation of the catalogue as a knowledge access portal is proposed, a "hybrid that combines the best features of a library catalogue with the best features of online portals" (Thomas, 2001). Metaphorically called "Open Sesame" it provides the user full access to the information and to several of its dimensions (ibidem).

A recap of the concept of the hybrid library (Oppenheim and Smithson, 1999), that integrates the physical, digital and the usage spaces, arises in this context. This model, that assumed a user centric view in the information systems arena, reappears today in the context of catalogue search services, supporting the coexistence of different search strategies, providing the function set known as "hybrid search for the modern library" (Aqualibrary) that includes in the same interface the search, refine and discover options. This can be interpreted as a realization of the catalogue functions enumerated in Frankfurt (IFLA, 2003).

This partitioning of the interface in the new catalogues results in a partitioning of behavioral patterns adopted for knowledge construction, perhaps meaning the assumption of the "hybrid" usage.

The idea of hybrid, first in the physical domain, then in the catalogue, then in the query and by extension in the user, denotes an attempt, and an adaptation problem at the same time, to the handling of elements of diverse types, sometimes of an undetermined nature. It also appears as a difficulty/possibility to manage paradoxes. It can denote the intention to approach dynamics and evolution with new reasoning structures. It means the preparation and incremental introduction of new services that focus the user in a less homogenous way, for new dimensions of space, time, usage and knowledge more versatile and manageable.

The concept of navigation and the implementation of languages that realize them mean in this context an opportunity to interpret the system adaptive response to mutation and regeneration of the collection, the usage and the knowledge. The concept of navigation also allows the inclusion of all the catalogue's functions in all of the formats already considered.

This navigation space is pursued in theory since the assumption of the Ranganhatan model in 1937 and the principle by Lubetzki later on. The former proposes an analysis by facets and the concept of Links and Chain, and the latter the principle of generating relations between the set of editions of a work directing the user to related items considering intellectual contents criteriathis is what was embodied in the Paris principles by the catalogue's functions and extended today in the FRBR to the concepts of EntityRelationship. 
The concept of navigation manifests itself in two related and complementary fronts. First as a set of internal principles of the cataloguing process itself: "in the context of the model, relationships serve as the vehicle for depicting the link between one entity and another, and thus as the means of assisting the user to "navigate" the universe that is represented in a bibliography, catalog, or bibliographic database (FRBR 5.1). The second is a system feature, specifically a collection coverage feature: "the OPAC should support a navigation function, giving access, not only to information about or in the library, but also to other library catalogues, databases of special information, databases of journal articles, electronic resources". (OPACs' Guidelines, 2003). The articulation of these two fronts materializes itself in the new International Cataloguing Standard that expresses, also using a hybrid approach, the "accumulation" of the whole ISBD family.

In the "First Principles of Interaction Design" and the "Ten Usability Heuristics" (Nielsen Norman Group) the concept of visible and transparent navigation is explored, to provide the user the comfort, the safety and the necessary illusion for a free formulation of questions.

A focus on the user as an actor involved in an enhanced concept of catalogue and collection is created in the articulation of these possible meanings of navigation. A platform is created, from which we see the emergence of the cognitive paradigm as a structuring model to know the user interacting, communicating with the system, and that catalyses the emergence of catalogues designed for "special publics" that although already having their own place in public libraries, require large, open and ergonomic question spaces.

\subsection{The children's catalogue: from a subspace to an effective place}

The children public demands to the public libraries have evolved, first to achieve their own physical spaces and then to require their own specific services. It can be noticed in the International Recommendations of Services for Children a growing recognition of this as a public on its own right and a consequent evolution of several specific services. These principles can be augmented with the Guideline for OPAC displays: "catalogues online have been evolving from centralized systems designed and controlled [...] to more open systems, more adaptable to the user, being fundamental then to design an OPAC appropriate to the intended audience (Yee,1999). Strategies specifically targeted to children public are specified such as "provide different interfaces to accommodate different users groups...graphics such as pictures of book covers and selectable visual icons for popular subjects and genres, large type, and simple language can help children to enjoy consulting the OPAC in a children's library" (4.1 Guidelines for OPACs). This suitability is specified in the recognition of the target groups described by the Guidelines for Children.

The recognition that the catalogue service has to adapt to the public under study brought some autonomy to this service and stimulated the study of the relations between the children and the catalogues searching for effective, interactive and efficient communication strategies.

Some research effort endorsed to multidisciplinary and transgenerational teams promote the search for an idea of "the" ideal interface based on the study of the interaction of children with technologies. They assume the ease of use of technological resources by children and try to understand their mental organization of concepts and their relationship with knowledge and how these evolve throughout their development. The catalogue of the Digital Library for Children is a practical example of the results of this effort.

The counterpart to these cognitive model based catalogues assumes most of the times a sub space/ sub catalogue format that inherits the features of its host system. The sub catalogue term can denote a metaphor of (sub) space, of (sub) collection and of (sub) usage. This is a common fact to all generations of catalogues. Having a substructure whose design is supported by some principles and techniques, these can reveal problems that hinder or limit the construction and free formulation of queries, or at least they ignore part of them. Even having a more ergonomic or appealing user interface that contributes to a more intuitive user experience with the system, the catalogue may lack the underlying components required for a dialogical construction.

In Portugal the services that for the children public started by the achievement of a physical space inside the library, a stimulus brought by the birth of the National Network of Public Reading (NNPR) (1988). This territorial conquest brought principles based on the dynamization of the physical space and the attraction of its public's attention. In a second step that occurred concurrently with the access availability, although partial, to the organizations through the World Wide Web (WWW), an effort was made to publicly advertise their reading and children group activities. At this stage, the children's pub- 
lic starts to emancipate itself, since, by assigning a program to a specific public, we are specifying a strategy and a space, naturally arising the space for target groups. This strategy, clearly limited to the usage of the physical space and the available resources, is evolving to allow for the provision of other services that became absolutely necessary, among which the OPAC is included.

Recently in the Portuguese Public Libraries, query spaces known as sub catalogues are slowly appearing. Far away from assuming themselves as independent query spaces, these are attached spaces, sometimes hidden inside the general catalogue, that provide information for children employing the same retrieval models designed for adults. There is an information access policy based on the integrated classical models where neither a distinction of publics nor a differentiation of search hypothesis exists.

\section{Portuguese Public Libraries survey}

A sample of 115 libraries spread across all the national territory was constituted-from a universe of about 330 libraries. $30 \%$ of the libraries in the sample are not part of the NNPR, $9 \%$ are BM3 (they serve a region with more than 50000 inhabitants), $23 \%$ are BM2 (they serve from 20000 to 50000 inhabitants) and $36 \%$ are BM1 (they serve regions with less than 20000 inhabitants). All libraries have a collection dedicated to the public under analysis. $91 \%$ of them have a children's space in their premises and the others don't.

It is observable through analysis of the children's service constitution date that this type of service started to appear in the 80's-just one of these services was born before 1980. However this information carries some uncertainty since $26 \%$ of the libraries that have this type of service didn't specify its constitution date.

In $80 \%$ of the institutions the children's space is divided in sub spaces such as baby's area, plastic arts area, story time area, game area, rookie readers' area, computers' area or pre-readers' area.

About half of the libraries have all the objects of their collection in one single space. One third has the objects of the collection distributed by two spaces and $10 \%$ of the libraries divide the objects of the children's collection in three distinct spaces. There are only two cases in which the number of spaces is more than 3 . The spaces are usually related with the objects physical support, e.g. audiovisual room, multimedia room or reading room.
The most visible fact derived from the analysis of the composition of the children's collections is that books represent, as we would expect, the vast majority of their objects- $92 \%$ is the mean size of this majority. The number of books is two orders of magnitude above the number of objects of the three types that follow-VHS tapes, CDs and DVDs-followed by the toys, the computer games and the magazines. A final remark about the collections' composition that is worth mentioning is that none of them includes a single e-book and book in digital form.

The access interface to the collection remains unknown in $8,7 \%$ of the sampled libraries because the questions to survey this topic weren't answered in these cases. $58,3 \%$ of the libraries have an integrated catalogue, i.e., the objects of the children's collection are treated just as any other object of the general fund and share the same access interface-the children's collection is embedded in the main fund. $24,3 \%$ don't have a catalogue available for information retrieval in the children's collection. In 8 of the surveyed libraries, representing less than $7 \%$ of the total, the children's collection has its own dedicated catalogue.

One can conclude that there are just a few catalogues dedicated to the children public. They are characterized by providing a partial access to the children's collection since there are objects available for use that aren't represented in the catalogue as the case of e.g., the toys, the games and the magazines, usually is.

\subsection{Critical interpretation of the results}

We investigated further the individuals of the dedicated children's catalogues group that are available online, and concluded that they are currently slightly better than other available catalogues in the Portuguese public libraries since they dedicate a part of their interfaces to the younger public, assuming though that they have their own, diverse, universe. However, the heterogeneity of the publics is just superficially explored and we can say though that this generation of catalogues merely "arranges" the publics, as a metaphor for "arranging" the collections. They haven't been designed considering the "target group" idiosyncrasies, internal management principles remain visible at the user interface and this is clearly not enough to provide the required communication environment. As a paradigmatic example, one of the catalogues classified as being dedicated to the children's public, provides an "audience" option to navigate in an "audience sensitive" manner, available only after the presentation of a search result. 
The principles for this age group segmentation are not explicit. It is something that can be interpreted as a mere possibility provided by the technological support, evidencing a clear underutilization of the developed work since it is hidden in an optional substructure of the interface.

It's also possible to observe from the analysis of the catalogues that the possible searches are segmented in space and time. The moments of navigation are interrupted by interaction ruptures that don't allow the employment of a continuous thought attitude to the semantic meanings' retrieval activity.

The observed catalogues' interfaces are based on Boolean search expressions. The user is allowed, after understanding this logic, to access the objects of the collection. The concept of navigation through the collection becomes partial and ineffective. The provided descriptions are characterized by asking the user to combine search equations that require knowledge of the cataloguing practice.

In general, there isn't any kind of user manual or help system to assist the users in their search activity. Adequate approaches to child users' interface design, such as particular graphical elements, are rarely present in these catalogues. It seems that the actual needs of this public are not recognized. A notable exception is available as an "ergonomic and intuitive catalogue" built as an image thesaurus. It is, however, an imported model from another cultural reality that presents links to reference sites whose contents are in English language-this catalogue works partially and is under construction.

In one of the cases the children's catalogue exists side by side with the general catalogue and the collection is divided in three segments: the book, the audio (that includes DVD) and the video (that includes also the DVD). In this case, before the relevance assigned to the physical support it would be desirable to understand to what extent one item is situated either as audio or as video.

The surveyed collections' compositions in general, don't follow the guidelines for children's services that suggest the inclusion of a variety of object types and emphasize the importance of the "new generation" materials. The excessive presence of books in the collections, when compared with other object types, is even more noticeable in the catalogue because in many cases, the other objects, although part of the collection, are not recorded in the catalogue. This fact obfuscates these other resources.
Paradoxically, the books may also loose interest focus.

\section{Improvement proposal and future work}

Our proposal is to devise an ontology at the catalogue substructure level in order to enhance the system that will be able to provide the user new, richer navigation experiences between the objects of the collection. Our aim is to redefine the items in wider semantic contexts emphasizing new attributes that shall expose the objects to a richer web of relationships, i.e. identify and relate the objects by affinity of subject, event and place in articulation with the physical person and corporate body entities. This information is in most cases readily available in the catalogues that usually include detailed bibliographic descriptions. However, this information is formally provided in a linear and sequential format. With the ontology, we expect to open the objects to their natural, intrinsic dynamics that is currently limited by the available system's presentation layer.

To clarify our idea, consider a concrete case in which the children's story Peter and the Wolf from Sergei Prokofiev is taken as an entity/concept. We envision a retrieval process whose outcome will include its and its related work's manifestations that existed in the past, exist in the present and may exist in the future. We include the possibility to relate events with time specifications that normally are not included in the catalogue. For example if a choreography with subject affinity is, was recently or will be in a near future, in exhibition in a "theatre near the user", we legitimate a place in the catalogue for it, enriching the user's search experience. The dynamics of the collection is revealed not only through the relations between its objects, but also by its ability to regenerate the resources and information about them. This is a principle that will contribute for the construction of an effective dialogue within the catalogue space.

This strategy aims also to promote the usage of the book. This has a strong impact potential since as surveyed, books abound in the Portuguese Public Libraries. Semantically emphasized by related resources of diverse nature, it will attain increased relevance and a wider context; it will be opened to other meanings; and deserve a personality that will attenuate a certain sense of banality in which it may fall due to its presence in such large number in a vast list or over a long shelve. To achieve this we shall value its physical dimensions, colors and illustration particularities and bring up from the physical 
description area along with the audience, organized groups of features that empower the users with effective tools for an easy identification of the objects they are searching for, whether concrete or idealized and that are sometimes very close to unique and artistic objects, not always rightfully valued. This is also a means of taking advantage of the valuable bibliographic descriptions produced in the libraries whose relevance is neither recognized nor made useful. It is a unique and standardized work that should clearly be made publicly available.

To formalize our work, we propose an application of the ABC Metadata Model (Lagoze \& Hunter, 2002) that presents an avant-garde attitude towards cultural organizations since it articulates biblioteconomy principles with principles of museums and archives integrating this vast universe in a communication paradigm that is recognized as the contemporary library, closer to the concept of "bibioteca" (Pinto 2003 p 65). The proposed model makes an interpretation of the FRBR (in its first version), and follows the methodology of the W3C's Resource Description Framework (RDF), being also applicable in "nonRDF" contexts. It interprets the entities in their existential facets contextualizing them in space and time. This way it allows for the possibility to reconstruct the object(s)' past history as well as to account for possible mutations in the future being prepared for new dimensions and dynamics, being suited to handle, for example, the volatile nature of the documents. In this sense, it allows the realization of the concept of relation/navigation in the intended sense.

Its syntax has contextualized autonomy, an advantage for an interpretation and usage of the tool in new cultural and linguistic environments, and most of all by the possibility to respect the mission of each organization and its target public. It provides tools that valuate the work done in the institutions so far, using it in new dimensions. It requires however, a clear definition of the concepts and their attributes and this implies a deep analysis of the concepts to consider, raising problems that are situated within the cataloguing discipline and that are only superficially handled in the FRBR. According to the mapping of the FRBR for the new International Cataloguing Standard the title proper Peter and the Wolf, for example, links to versions of the work or to manifestations or to attributes of a work or to attributes of an expression. It is clear the need to define a consistent strategy that respects the nature of the objects in context, the cataloguing practice and the user interests. The model also specifies that "abstraction category" are never in the context of a situation" (3.3), requiring that it manifests. This interpretation seems questionable if considering the manuscript or painting objects domains.

Part of the literature for children has its roots in the oral literature and incarnated the short story format, being usually known to the user through its title. With some similarities with anonymous classics, the various versions of a work correspond to little variations in space, time or character. This factor should be equated in order to realize a web of relations that allow the users to capture the dynamics inherent to "works" of this nature. This will require a reinterpretation of the "event" domain and of the defined attributes.

The model allows the construction of search equations close to natural language and acts as if the semantic structure is well defined. However, we want to explore further the possibility "to change the way a dialogue is developing by changing the rules that define the behavior" (Quaresma, 1997) of the user and also to recognize and record these dialogues to be able to compare specific usage profiles.

\section{Conclusions}

There is an ongoing practice in the Portuguese public libraries denoting a generally adopted strategy aiming to attract new young publics. The Libraries' facilities layout design based on age group criteria and the dinamization of each of these subspaces with policies that take their target publics into account is a clear evidence of this fact. This dynamic shall continue and shall be extended to other services. It will result in the recognition of the children's catalogue with the capacity to assume its own personality and autonomy from within its host system. This strategy has merely started in the Portuguese public library and keeps following an internal organization perspective that doesn't yet consider the diversity of its young publics.

These young publics evolve with technology. They recognize the dynamics and evolution as an integral part of the nature of things, of their own relation with the objects. This fact can be due to either their yet unrestricted imagination or to their familiarity with the new systems. They easily accept the idea of "rematerialization" and are thought naturally receptive to the communication paradigm of the contemporary library. They have potentially more ability to deal with the innovation and complexity, sometimes only apparent, of the spatial and temporal dimensions. The availability of spaces that satisfy these needs is up to the organizations. They shall maintain a clear view of this reality and sustain an offer of always appealing collections, with 
with variety and in constant renewal, built according to the diversity of public profiles. This renewal can be made by offering information about new ways of looking at the objects and new relations with objects and resources available online making the concept of navigation effective.

\section{References}

Aquabrowser Library. http://www.medialab.nl/index.asp (2007-05-27).

Arellano, Filipe (1994). Comparación de dos catálogos en línea: CD-UNAM y BISON. Centro Universitario de Investigaciones Bibliotecológicas de la Universidad Nacional Autónoma se México, 1994. http://www.dgbiblio. unam.mx/servicios/dgb/publicdgb/bole/fulltext/vollX2/bis on.html (2007-03-20).

Byrum, John D. (2005). Recommandations pour une amélioration urgente des catalogues publics (OPACs). 71st IFLA General Conference and Council. Oslo, 2005. http://www.ifla.org/lV/ifla71/Programme.htm (2007-0210).

Ding, Ying (2001). A review of ontologies with the Semantic Web in view. //Journal of Information Science 2001. 377384. http://jis.sagepub.com/egi/content/abstract/27/6/377 (2007-02-27).

IFLA Cataloguing Section (2007). Mapping de ISBD Elements to FRBR Entity Attributes and Relationship. http://www.ifla.org/VII/s13/pubs/ISBD-FRBRmappingFinal.pdf (2007-03-2).

IFLA Cataloguing Principles: Steps towards on a international cataloguing code (2003). Report from the 1st Meeting of Experts on International Cataloguing Code, Frankfurt 2003. http://www.ifla.org/V/pr/Bibliographiccontrolvol26-es.pdf (2007-04-20).

IFLA (2003). Guidelines for Online Public Access Catalog (OPAC) Displays. [Draft for Worldwide Review]. 2003.http://www.ifla.org/VII/s13/guide/opacguide03.pdf (2007-02-10).

IFLA Study Group on the Functional Requirements for Bibliographic Records (1998). Functional Requirements for Bibliographic Record. München: Saur. 1998. http://www.ifla.org/VII/s13/frbr/frbr.htm (2007-03-20).
IFLA (2003). The background text to the Guidelines for Children's Libraries 2003. http://www.ifla.org/VII/s10/pubs/guidelinesbackgrounden.pdf (2007-03-20).

Lagoze, Carl; Hunter, Jane (2002). The ABC Ontology and Model. // Journal of Digital Information 2. Publications of the School of Information Technology and Electrical Engineering. 2002. http://espace.library.uq.edu.au/view.php ?pid=UQ:7876 (2007-02-20).

Lubetzky, Seymour (1985). The objectives of the catalog. // Carpenter, Michael; Svenonius, Elaine. Foundations of Cataloguing: A Sourcebook. Littleton, CO: Libraries Unlimited, 1985. 186-191.

Nielsen Norman Group. First principles of Interactio Design. Ten Usability Heuristics http://www.asktog.com/ basics/firstPrinciples.html (2007-05-20)

Online Computer Library Center http://www.worldcat.org/ ;http://fictionfinder.oclc.org/ (2007-05-1).

Oppenheim, Charles; Smithson, Daniel (1999). What is the hybrid library. // Journal of Information Science DOI: 10.1177/016555159902500202 (25-97) $1999 . \quad 1-17$. http://jis.sagepub.com/cgi/content/abstract/25/2/97 (2007 -02-27).

Pinto Molina, Maria; Garcia Marco, F. Javier; Agustin LaCruz, Maria Del Cármen (2002). Indización y resumen de documentos digitales y multimédia: Técnicas y procedimientos. Gijón: Ediciones Trea, 2002.

Quaresma, Paulo (1997). Inferências de atitudes em diálogos. PhD thesis. Faculdade de Ciências e Tecnologia, Universidade Nova de Lisboa, 1997.http://www.di. uevora.pt/ pq/papers/tesepq.pdf (2007-05-2).

Ranganhathan, S. R. (1962). Classified Catalog Code. London: Asia Publishing House, 1962.

Thomas, Sarah E. (2001). The Catalog as Portal to the Internet. Proceedings of the Bicentennial Conference on Bibliographic Control for the New Millennium: Confronting the Challenges of Networked Resources and the Web, Washington, D. C.: Cataloguing Distribution Service, 2001. http://www.loc.gov/catdir/bibcontrol/thomas _paper.html (2007-02-20).

Yee, Martha (1999). Guideline for Opacs displays .65th IFLA Council and General Conference. Bangkok, Thailand. 1999. http://www.ifla.org/IV/ifla65/papers/098-131e.htm (2007-01-03). 